\title{
The Effect of Environmental Stringency on End-Use Energy Prices: Evidence From High-Income Country Panels
}

\author{
Brantley Liddle' \\ ${ }^{1}$ Energy Studies Institute, National University of Singapore, Singapore \\ Keywords: cross-sectionally dependent dynamic panels, environmental stringency, end-use energy prices \\ https://doi.org/10.46557/001c.17853
}

\section{Energy RESEARCH LETTERS}

Vol. 1, Issue 4, 2020

We estimate environmental stringency's influence on end-use energy prices for high-income countries by examining the impact of four measures of environmental stringency on residential and industrial electricity prices and road gasoline and diesel prices. While we uncover some such influence on electricity prices, the most substantial and robust evidence for environmental stringency impacting end-use prices is for the effect of total environmental tax/GDP and energy tax/GDP on diesel and gasoline prices.

\section{Introduction}

Energy consumption is a well-recognized source of several environmental problems (e.g., smog, acid rain, climate change). Yet, there is a concern that stringent environmental policies may have a negative effect on energy consumers through price increases. For example, the World Bank (2019, p. 3) reports that: "Only 20 percent of global GHG emissions are covered by a carbon price and less than 5 percent of those are currently priced at levels consistent with reaching the temperature goals of the Paris Agreement." Of course, the goal of some stringent environmental policies is to discourage the use of certain forms of energy (e.g., those sourced from fossil fuels). However, there has been limited studies on the impact of environmental policies on energy prices. This paper aims to fill this research gap by examining the impact of environmental stringency on enduse electricity (residential and industrial) and road (gasoline and diesel) prices in the OECD/high-income countries.

The study closest to ours is Dike (2014), who used carbon emissions (divided by GDP) as a proxy for climate change mitigation efforts in order to determine such efforts' impact on crude oil prices. While the availability of measures of environmental stringency has grown, most analyses of the impact of environmental policy have focused on growth, productivity, and trade-related variables and have produced conflicting results (Galeotti et al., 2020). Indeed, no study has used data to assess stringency's impact on end-use energy prices, even though such knowledge is of clear importance for policy.

\section{Data and methods}

Following Dike (2014), we use a partial adjustment model that allows prices to adapt overtime to stringency:

$$
\text { In } \text { Price }_{i t}=\alpha_{i}+\beta_{1} \text { ln } \text { Price }_{i t-1}+\beta_{2} \text { ln Policy }_{i t}+\varepsilon_{i t}
$$

where subscripts it denote the $i^{\text {th }}$ cross-section and $t^{\text {th }}$ time period, Price is one of the four end-use prices, Policy is one of the four environmental stringency measures, $\alpha$ is a crosssectional specific constant, $\beta \mathrm{S}$ are cross-sectional specific coefficients to be estimated, and $\varepsilon$ is the error term. So, the expected evidence for stringency's impact would be a statistically significant, positive coefficient for $\beta_{2}$.

All end-use price data are from Enerdata's Global Energy and $\mathrm{CO}_{2}$ database. ${ }^{1}$ Electricity prices for residential and industrial sectors are in 2015 US cents using purchasing power parity (PPP) per kilowatt hour, and premium gasoline and diesel prices are in 2015 USD using PPP per liter. Premium gasoline prices are highly correlated with unleaded gasoline prices, as are diesel prices with commercial diesel prices. The availability of the (mostly balanced) annual price data is for the 1978-2016 period.

One of the measures of environmental stringency discussed in Galeotti et al. (2020) that has the most extensive coverage is tax share of GDP. Annual tax data are from the OECD's database of Policy Instruments for the Environment (PINE). We consider taxes under two categories: (1) energy tax/GDP (tax revenue per capita in 2010 USD using PPP), which consists of taxes on energy products (e.g., transportation fuels and electricity) and includes all $\mathrm{CO}_{2}$-related taxes; and (2) total environmental tax/GDP (same units), which includes those energy taxes plus (i) taxes on the sale of transport equipment, taxes on ownership and/or registration of motor vehicles, and other transport-related taxes; (ii) taxes on emissions of sulfur oxides, nitrogen oxides, chlorofluorocarbons, and hydrofluorocarbons, discharge of wastewater, disposal of solid waste, and other waste-related taxes; and (iii) taxes on water extrac- 
tion, forest products, hunting and fishing, mining royalties, and excavation taxes. The (unbalanced) tax data span the 1994-2018 period.

Hence, the tax-based panel dataset runs from 1994-2016 and includes observations from 36 high-income countries ${ }^{2}$ (34 OECD countries ${ }^{3}$ plus high-income, non-OECD countries, Cyprus and Malta). The data are mostly/highly balanced. Each included country has at least 20 observations, and the average for each panel is 23 observations.

Naturally, diesel and gasoline are fossil fuels; however, the average share of fossil fuels used to generate electricity for the OECD is around 50\%, but the individual country averages run the gamut from effectively no fossil fuels (e.g., Norway, Sweden) to only fossil fuels (e.g., Israel). Furthermore, among fossil fuels, less carbon-intensive natural gas typically is the most commonly employed in electricity generation. Thus, we expect the tax-based measures to impact the road fuels more than electricity.

In the spirit of Dike (2014), who focused on carbon emissions, we consider the emissions intensity of two highly regulated, local/regional pollutants too-fine particulate matter (PM 2.5) and sulfur oxides (SOx, in kg per 1,000 in 2010 USD PPP). The OECD collects data on man-made emissions (that exclude international aviation and maritime transport) of both pollutants with respect to mobile and stationary sources. Fine particle (PM 2.5) emissions come from power plants, the burning of coal and wood, and vehicle exhausts. The main source of sulfur oxides is the combustion of sulfur-containing fuels like coal and petroleum. The emissions intensity for both pollutants has declined substantially. Since 1990, the OECD average emissions intensity for sulfur has dropped by over $85 \%$ and for PM 2.5 by over $70 \%$. The sulfur/PM emissions data run from 1990-2017.

However, we can combine the OECD sulfur data with sulfur data from NASA Socioeconomic Data and Applications Center ${ }^{4}$ to create a relatively long sulfur intensity series. So, the sulfur-focused panel dataset runs from 1978-2016 and includes (mostly balanced) observations from 32 OECD countries (including Turkey); whereas, the PM-focused panel runs from 1990-2016 and includes (mostly balanced) observations from 22 OECD countries (including Turkey).

While Galeotti et al. (2020) argued that emission intensities that have not been adjusted for potential emissions are not good cross-country indicators of stringency, we intend using methods that focus on within country variance overtime. Thus, we believe that actual emissions should be a reasonable proxy of stringency in that time dimension. The emissions intensity measures aim to capture the impact of command and control-type measures (like requiring scrubbers) in addition to the impact of tax measures. While transport is a source of both PM and SOx emissions (and exhaust technology is the main way to control particulate transport emissions), the burning of coal is the primary source of sulfur emissions. As a result, we expect that emissions intensity would have a greater impact on electricity prices than on road fuel prices.

Table 1 displays basic summary statistics and the results of the Pesaran (2015) cross-sectional dependence (CD) test. ${ }^{5}$ For all the variables, the $\mathrm{CD}$ test rejects the null hypothesis of weak cross-sectional dependence. For end-use prices and measures of stringency, cross-sectional correlation/dependence is expected because of linkages like international trade (prices) and environmental agreements like the Montreal Protocol (stringency). The differences between the mean correlation coefficients and the mean absolute value correlation coefficients suggest that for taxes and electricity prices, some correlations are negative (as well as positive). ${ }^{6}$ By contrast, emission intensities and road fuel prices tend to co-move among the countries since the mean correlation coefficients and the mean absolute value correlation coefficients are either the same or very close.

We employ the Dynamic Common Correlated Effects (DCCE) estimator of Chudik and Pesaran (2015). ${ }^{7}$ The DCCE is a mean group estimator (MG) that first estimates crosssectional specific regressions and then averages those estimated individual-country coefficients to arrive at panel coefficients. DCCE is part of the Pesaran (2006) Common Correlated Effects (CCE)-family of estimators that account for the presence of unobserved common factors by including in the regression cross-sectional averages of the dependent and independent variables. However, the CCE estimator is not consistent in dynamic panels since the lagged dependent variable is not strictly exogenous; thus, the DCCE estimator includes additional lags of the cross-sectional means to become consistent again. The choice of lags is a tradeoff between maintaining enough observations to accurately estimate the country-specific parameters of interest and having a sufficient number of lags to ensure that common factors are well approximated. Thus, for our shorter panels, we consider one set of lags of the cross-sectional averages, and for the longer-sulfur intensity-focused panel we include two sets of such lags.

Yet, dynamic models estimated with panel data are subject to a downward bias. However, Chudik and Pesaran (2015) show that the DCCE approach performs well-i.e., the approach is free of this dynamic panel bias-when the parameter of interest is the average slope of the regressor(s)

\footnotetext{
2 Upper-middle-income country, Turkey, is not considered high-income according to the World Bank.

3 Only three OECD countries are not included because of lack of data: Iceland, Mexico, and 2020-ascension Columbia.

4 Anthropogenic Sulfur Dioxide Emissions, 1850-2005: National and Regional Data Set by Source Category, Version 2.86. http://dx.doi.org/ 10.7927/H49884X9.

5 This test is implemented via the Stata command xtcd2, which was developed by Jan Ditzen.

6 The correlation coefficients are calculated via the Stata command xtcd, which was developed by Markus Eberhardt.

7 The Dynamic Common Correlated Effects estimator of Chudik and Pesaran (2015) is implemented by Stata command xtmg-which was developed by Markus Eberhardt.
} 
Table 1. Summary statistics and Pesaran (2015) CD test results

\begin{tabular}{|c|c|c|c|c|c|c|c|}
\hline & Mean & $\begin{array}{l}\text { Std. } \\
\text { dev. }\end{array}$ & Min & Max & $\begin{array}{l}\text { CD- } \\
\text { test }\end{array}$ & $\bar{\rho}$ & $\begin{array}{c}\text { Abs. } \\
\bar{\rho}\end{array}$ \\
\hline Total environmental tax share GDP (\%) & 2.5 & 0.8 & 0.3 & 5.4 & $11.7^{*}$ & 0.096 & 0.46 \\
\hline Energy tax share GDP (\%) & 1.6 & 0.6 & 0.01 & 3.7 & $6.6^{*}$ & 0.053 & 0.50 \\
\hline PM/GDP (Kg per 1,000 2010 USD PPP) & 0.3 & 0.4 & 0.01 & 2.3 & $69.9^{*}$ & 0.89 & 0.89 \\
\hline SO/GDP (Kg per 1,000 2010 USD PPP) & 1.8 & 2.4 & 0.01 & 13.9 & $118.9^{*}$ & 0.89 & 0.89 \\
\hline $\begin{array}{l}\text { Residential electricity price ( } 2015 \text { US cents PPP/ } \\
\text { kWh) }\end{array}$ & 21.7 & 8.2 & 4.6 & 48.1 & $16.0^{*}$ & 0.13 & 0.44 \\
\hline $\begin{array}{l}\text { Industry electricity price (2015 US cents PPP/ } \\
\text { kWh) }\end{array}$ & 10.7 & 3.9 & 2.8 & 30.3 & $33.2^{*}$ & 0.25 & 0.43 \\
\hline Road diesel price (2015 USD PPP/liter) & 1.5 & 0.7 & 0.3 & 4.7 & $74.8^{*}$ & 0.59 & 0.63 \\
\hline Road gasoline price (2015 USD PPP/liter) & 1.9 & 0.9 & 0.4 & 7.2 & $62.0^{*}$ & 0.49 & 0.56 \\
\hline
\end{tabular}

Notes: This table reports selected descriptive statistics; * $p$-value $<0.001$. Null hypothesis is weak cross-sectional dependence; the CD-test is performed on variables in natural logarithmic form; $\bar{\rho}=$ mean correlation coefficient; and Abs. $\bar{\rho}=$ mean absolute value correlation coefficient.

even in the case where $N$ and $T$ are relatively small. By contrast, the mean coefficient of the lagged dependent variable can suffer from dynamic panel bias unless $T$ is sufficiently large. So, we focus on the estimates of the coefficient for the stringency measure, i.e., the $\beta_{2}$ from Equation (1) (and do not divide $\beta_{2}$ by $\beta_{1}$ ).

For diagnostics, first we run the CD test on the residuals of a MG regression and report the $p$-value of the test statistic and the mean correlation coefficient to demonstrate that one needs to account for strong cross-sectional dependence. We run the CD test on the DCCE residuals as well and report both above-mentioned values to show the extent to which the cross-sectional average terms address this dependence. Next, we consider a test based on Pesaran and Yamagata (2008), which compares the difference between coefficients obtained from a pooled, fixed effects regression to the coefficients obtained from the DCCE regression, ${ }^{8}$ to confirm that the country-specific slopes are not homogenous. Finally, we run the Pesaran (2007) panel unit root test for heterogeneous panels (CIPS), which allows for crosssectional dependence to be caused by a single (unobserved) common factor, ${ }^{9}$ on the DCCE residuals to confirm that they are stationary.

\section{Results and discussion}

The regression results for each end-use price dependent variable and for the four different independent variable measures of environmental stringency are displayed in Table 2. In terms of diagnostics, all the regression residuals are stationary (as demonstrated by the CIPS test). Furthermore, in each regression equal slopes for all countries is rejected at the highest levels (via the Pesaran and Yamagata test), as is weak dependence for a MG regression (via the CD test). Thus, both decisions to (i) address cross-sectional de- pendence via including cross-sectional averages and (ii) allow for country-specific coefficients are necessary. For most regressions, the CD test on the DCCE residuals cannot reject weak cross-sectional dependence. For the regression of gasoline price on SO/GDP, the DCCE residuals do reject weak cross-sectional dependence, but the resulting mean correlation coefficient for the DCCE regression is (more than) an order of magnitude smaller than for the MG regression (which is the case for all road price regressions); hence, adding the cross-sectional average terms has clearly mitigated any such dependence.

Having confirmed that all regressions are well specified, we turn our attention to the results. The coefficients on the lagged dependent variables are always statistically significant and range from 0.5 to 0.75 (not shown in the table for brevity). There is some evidence that both energy tax/ GDP and PM/GDP had some influence on residential electricity prices (although energy tax is only marginally significant). Alternatively, for industry electricity, total environmental tax/GDP and SO/GDP led to higher prices (but SO is only marginally significant). It is not clear why the results for residential and industrial electricity would be different. Since total environment taxes include taxes on several pollutants, including SO (and other waste-related pollutants but, apparently not, PM), the results for industrial electricity are consistent in this respect.

The most substantial, robust evidence (in terms of statistical significance) for environmental stringency impacting end-use prices is for the stringency impact of both total environmental tax/GDP and energy tax/GDP upon both road diesel and gasoline prices. As mentioned earlier, these relationships should not be surprising since energy and environmental taxes include taxes on transportation fuels as well as all $\mathrm{CO}_{2}$-related taxes and vehicles are not the major sources of PM and SO. In sum, all the significant coefficients

8 That test is implemented via Stata command xthst, which was written by Tore Bersvendsen and Jan Ditzen.

9 This test is implemented via the Stata command pescadf, which was developed by Piotr Lewandowski. 
Table 2. Regression results

\begin{tabular}{|c|c|c|c|c|}
\hline $\begin{array}{l}\text { Stringency measure/independent } \\
\text { variable (time span) }\end{array}$ & $\begin{array}{l}\text { Total Environment Tax/ } \\
\text { GDP (1994-2016) }\end{array}$ & $\begin{array}{l}\text { Energy Tax/GDP } \\
(1994-2016)\end{array}$ & $\begin{array}{c}\text { PM/GDP } \\
(1990-2016)\end{array}$ & $\begin{array}{c}\text { SO/GDP } \\
(1978-2016)\end{array}$ \\
\hline \multicolumn{5}{|c|}{ Dependent Variable: Residential electricity price } \\
\hline Coefficient of Stringency measure & $\begin{array}{c}0.091 \\
(0.062)\end{array}$ & $\begin{array}{l}0.076^{*} \\
(0.043)\end{array}$ & $\begin{array}{l}0.090^{* *} \\
(0.043)\end{array}$ & $\begin{array}{l}-0.0068 \\
(0.023)\end{array}$ \\
\hline Obs (N) & $736(34)$ & $735(34)$ & $560(22)$ & $1125(32)$ \\
\hline MG CD: p-value; $\bar{\rho}$ & $0.000 ; 0.046$ & $0.000 ; 0.044$ & $0.000 ; 0.086$ & $0.000 ; 0.073$ \\
\hline DCCE CD: p-value; $\bar{\rho}$ & $0.292 ; 0.010$ & $0.013 ; 0.022$ & $0.132 ;-0.022$ & $\begin{array}{l}0.287 \\
-0.011\end{array}$ \\
\hline P-Y adj. delta: $p$-value & 0.000 & 0.000 & 0.000 & 0.000 \\
\hline DCCE CIPS & $\mathrm{I}(0)$ & $\mathrm{I}(0)$ & $\mathrm{I}(0)$ & $\mathrm{I}(0)$ \\
\hline \multicolumn{5}{|c|}{ Dependent Variable: Industry electricity price } \\
\hline Coefficient of Stringency measure & $\begin{array}{l}0.13^{* *} \\
(0.060)\end{array}$ & $\begin{array}{l}0.103 \\
(0.064)\end{array}$ & $\begin{array}{c}0.064 \\
(0.072)\end{array}$ & $\begin{array}{l}0.038^{*} \\
(0.021)\end{array}$ \\
\hline Obs (N) & $759(35)$ & $758(35)$ & $540(21)$ & 1105(31) \\
\hline MG CD: p-value; $\bar{\rho}$ & $0.000 ; 0.095$ & $0.000 ; 0.099$ & $0.000 ; 0.191$ & $0.000 ; 0.144$ \\
\hline DCCE CD: p-value; $\bar{\rho}$ & $0.060 ;-0.017$ & $0.024 ;-0.021$ & $0.277 ;-0.015$ & $\begin{array}{l}0.891 \\
-0.003\end{array}$ \\
\hline P-Y adj. delta: $\mathrm{p}$-value & 0.001 & 0.000 & 0.000 & 0.000 \\
\hline DCCE CIPS & $\mathrm{I}(0)$ & $\mathrm{I}(0)$ & $\mathrm{I}(0)$ & $\mathrm{I}(0)$ \\
\hline \multicolumn{5}{|c|}{ Dependent Variable: Road diesel price } \\
\hline Coefficient of Stringency measure & $\begin{array}{l}0.11^{* * *} \\
(0.037)\end{array}$ & $\begin{array}{l}0.11^{* * *} \\
(0.036)\end{array}$ & $\begin{array}{l}-0.049 \\
(0.033)\end{array}$ & $\begin{array}{l}0.019 \\
(0.018)\end{array}$ \\
\hline Obs (N) & $737(34)$ & $737(34)$ & $558(22)$ & $1120(32)$ \\
\hline MG CD: p-value; $\bar{\rho}$ & $0.000 ; 0.694$ & $0.000 ; 0.716$ & $0.000 ; 0.729$ & $0.000 ; 0.636$ \\
\hline DCCE CD: $\mathrm{p}$-value; $\bar{\rho}$ & $0.307 ; 0.008$ & $0.498 ;-0.007$ & $0.339 ;-0.018$ & $\begin{array}{l}0.436 \\
-0.015\end{array}$ \\
\hline P-Y adj. delta: $p$-value & 0.000 & 0.000 & 0.000 & 0.000 \\
\hline DCCE CIPS & $\mathrm{I}(0)$ & $\mathrm{I}(0)$ & $\mathrm{I}(0)$ & $\mathrm{I}(0)$ \\
\hline \multicolumn{5}{|c|}{ Dependent Variable: Road gasoline price } \\
\hline Coefficient of Stringency measure & $\begin{array}{l}0.11^{* * *} \\
(0.037)\end{array}$ & $\begin{array}{l}0.057^{* *} \\
(0.029)\end{array}$ & $\begin{array}{l}0.0042 \\
(0.026)\end{array}$ & $\begin{array}{l}-0.015 \\
(0.015)\end{array}$ \\
\hline Obs (N) & $758(35)$ & $758(35)$ & $558(22)$ & $1120(32)$ \\
\hline MG CD: p-value; $\bar{\rho}$ & $0.000 ; 0.641$ & $0.000 ; 0.669$ & $0.000 ; 0.698$ & $0.000 ; 0.574$ \\
\hline DCCE CD: p-value; $\bar{\rho}$ & $0.279 ; 0.010$ & $0.511 ; 0.005$ & $0.898 ; 0.000$ & $\begin{array}{l}0.060 \\
-0.020\end{array}$ \\
\hline P-Y adj. delta: $p$-value & 0.000 & 0.000 & 0.000 & 0.000 \\
\hline DCCE CIPS & $\mathrm{I}(0)$ & $\mathrm{I}(0)$ & $\mathrm{I}(0)$ & $\mathrm{I}(0)$ \\
\hline
\end{tabular}

This table reports the papers main results. Asterisks $* * * * * *$, and $*$ indicate statistical significance at the $1 \%, 5 \%$ and $10 \%$ levels of significance, respectively. Standard errors are in parentheses below the coefficient. Obs $(\mathrm{N})=$ observations (cross-sections). MG is the mean group regression (no cross-section average terms); $C D$ is the Pesaran (2015) $C D$ test statistic $p$-value; and ; $\bar{\rho}$ is the corresponding mean correlation coefficient of the residuals. The null hypothesis is weak cross-sectional dependence. DCCE is the MG with cross-sectional average terms plus one or two additional lags of all cross-sectional average terms. P-Y adj. delta= Pesaran and Yamagata (2008) test for slope homogeneity. The null hypothesis is that the slope coefficients are the same. CIPS is the Pesaran (2007) CIPS test on residuals; and I(0)=stationary.

are small (on the order of 0.1 ).

\section{Conclusions}

It is reassuring that PM 2.5 and SOx emissions have reduced substantially since the 1980-1990s, but this decline has had little impact on energy consumers' end-use prices. On the other hand, the relatively low coefficients for total environmental tax/GDP and energy tax/GDP suggest that a carbon tax may have a limited impact on influencing energy consumption. On the positive side, we find that taxes typically have a larger impact on road prices than electricity prices, and recent evidence elsewhere is that the price elasticities for demand among high-income/OECD countries are much larger (in absolute terms) for road gasoline and road diesel than for residential and industrial electricity (e.g., see Liddle \& Huntington, 2020a, 2020b; Liddle \& Hasanov, 2020). ${ }^{10}$

This paper provides a first analysis on the association be- 
tween end-use energy prices and measures of environmental stringency. In addition to developing improved measures of emissions intensities that adjust for potential emissions (as discussed in Galeotti et al., 2020), considering the tax rates per unit of emissions for specific fuels (like gasoline, coal) would allow for a more direct analysis (were such data available). Also, we used a reduced-form model of the relationship between end-use prices and environmental stringency. However, one could construct a more comprehensive model of each fuel's supply and demand functions to derive the incremental effect of introducing pollution taxes/stringency policies. Lastly, to understand fully the effect of environmental taxes/regulations on the electric power sector, one should take some account of the diversity of this sector across countries, e.g., the extent and nature of price regulation, the level of competition in the sector, and the pollution intensity of the marginal fuel (e.g., natural gas, coal vs. hydro, wind). ${ }^{11}$

\section{Acknowledgements}

I would like to thank the Editor and anonymous referee for their valuable feedback in improving the paper to its current form.

This is an open-access article distributed under the terms of the Creative Commons Attribution 4.0 International License (CCBY-SA-4.0). View this license's legal deed at https://creativecommons.org/licenses/by-sa/4.0 and legal code at https://creativecommons.org/licenses/by-sa/4.0/legalcode for more information.

10 Those estimated price elasticities were: $-0.74,-0.35,-0.22$, and -0.25 for road gasoline, road diesel, residential electricity, and industry electricity, respectively.

11 I owe credit to an anonymous referee for several of these future work suggestions. 


\section{REFERENCES}

Chudik, A., \& Pesaran, M. H. (2015). Common correlated effects estimation of heterogeneous dynamic panel data models with weakly exogenous regressions. Journal of Econometrics, 188(2), 393-420.

Dike, J. C. (2014). Does climate change mitigation activity affect crude oil prices? Evidence from dynamic panel model. Journal of Energy, 2014, 1-9. $\underline{\mathrm{h}}$ ttps://doi.org/10.1155/2014/514029

Galeotti, M., Salini, S., \& Verdolini, E. (2020). Measuring environmental policy stringency: Approaches, validity, and impact on environmental innovation and energy efficiency. Energy Policy, 136, 111052. https://doi.org/10.1016/i.enpol.2019.111052

Liddle, B., \& Hasanov, F. (2020). Industry Electricity Price and Output Elasticities: An OECD \& non-OECD Country Common Factor Dynamic Panel Analysis. USAEE Working Paper No. 20-434. https://ssrn.com/a bstract $=3552653$

Liddle, B., \& Huntington, H. (2020a). 'On the Road Again': A 118 Country Panel Analysis of Gasoline and Diesel Demand. Transportation Research A: Policy and Practice, 142, 151-167. https://doi.org/10.1016/j.t ra.2020.10.015
Liddle, B., \& Huntington, H. (2020b). How Prices, Income, and Weather Shape Household Electricity Demand in High-Income and Middle-Income Countries. Energy Economics. https://doi.org/10.101 6/j.eneco.2020.104995

Pesaran, M. H. (2006). Estimation and inference in large heterogeneous panels with a multifactor error structure. Econometrica, 74(4), 967-1012. https://do i.org/10.1111/j.1468-0262.2006.00692.x

Pesaran, M. H. (2007). A simple panel unit root test in the presence of cross-section dependence. Journal of Applied Econometrics, 22, 265-312.

Pesaran, M. H. (2015). Testing weak cross-sectional dependence in large panels. Econometric Reviews, 34, 1089-1117.

Pesaran, M. H., \& Yamagata, T. (2008). Testing slope homogeneity in large panels. Journal of Econometrics, 142, 50-93.

World Bank Group. (2019, June). State and trends in carbon pricing 2019. hdl:10986/31755 